\title{
MANEJO FLORESTAL DE UM CLONE DE Eucalyptus urophylla vs. Eucalyptus grandis VISANDO A EFICIÊNCIA NO USO DA ÁGUA E NUTRIENTES.
}

Renato de Araújo Ferreira, Plínio Carielo, João Luiz Dal Ponte Filho, Luciana Duque Silva, Juliana Paula Oliveira da Silva, Lara Beatriz de Oliveira, Monique Prado de Andrade, Douglas Rogério Estevam Peruchi, Heloisa Barossi Trevisan, Walisson Antonio Oliveira Coutinho, Bruno Vicente do Amaral, Emerson Ferreira de Oliveira, João Pedro de Freitas Melo e Vinícius Matheus Rodrigues Paulino

Centro Estadual de Educação Tecnológica Paula Souza, Escola Técnica Estadual Prof. Dr. Antonio Eufrásio de Toledo - ETEC, Técnico em Florestas, Presidente Prudente, SP. E-mail: renato.ferreira26@etec.sp.gov.br

\section{RESUMO}

O presente trabalho teve como objetivo avaliar o desenvolvimento do clone de Eucalyptus urophylla vs. Eucalyptus grandis submetido a diferentes espaçamentos e adubação potássica no município de Presidente Prudente-SP, visando a eficiência no uso da água e nutrientes, consequentemente melhor desenvolvimento. A avaliação realizou-se aos 24 meses após o plantio. Foi coletado o Diâmetro a Altura do Peito (DAP) $(\mathrm{cm})(1,30 \mathrm{~m})$, com uso da suta mecânica Haglof e a altura total $(\mathrm{HT})(\mathrm{m})$, com uso do clinômetro Eletrônico Haglof. Após a realização da avaliação, observa-se que aos 24 meses após o plantio, dentre os fatores espaçamentos e adubação potássica testados, apenas o espaçamento interferiu significativamente no clone de Eucalyptus urophylla vs. Eucalyptus grandis, em relação a variável DAP, sendo os tratamentos no arranjo $3 \times 4 \mathrm{~m}$ o que obtiveram melhor resultado.

Palavras-chave: Silvicultura, eucalipto, espaçamento, potássio.

\section{FOREST MANAGEMENT OF A CLONE OF Eucalyptus urophylla vs. Eucalyptus grandis SEEKING EFFICIENCY IN THE USE OF WATER AND NUTRIENTS.}

\begin{abstract}
This study aimed to evaluate the development of Eucalyptus urophylla clone vs. Eucalyptus grandis under different spacings and potassium fertilization in the city of Presidente Prudente -SP, aiming at efficient use of water and nutrients, thus better development. The evaluation was performed at 24 months after planting. It collected the diameter at breast height $(\mathrm{DBH})(\mathrm{cm})(1.30 \mathrm{~m})$, with use of mechanical caliper Haglöf and the total height $(\mathrm{TH})(\mathrm{m})$ using the Haglöf Electronic Clinometer. Upon completion of the evaluation, it is observed that at 24 months after planting, among spacings and tested potassium fertilization factors, only the spacing interfered significantly in Eucalyptus urophylla clone vs. Eucalyptus grandis, for DAP variable, and treatments in the arrangement $3 \times 4 \mathrm{~m}$ which obtained better results.
\end{abstract}

Keywords: Forestry, eucalyptus, spacing, potassium. 


\section{INTRODUÇÃO}

O gênero Eucalyptus pertencente a família Myrtaceae é uma planta originária da Austrália, exceto por duas espécies, o E. uroplylla e E. deglupta. Foi introduzido no Brasil em 1868 nos estados de Rio Grande do Sul e Rio Janeiro. Mas foi entre 1904 e 1909 que Edmundo Navarro de Andrade desenvolveu trabalhos experimentais no Horto de Jundiaí -SP utilizando o eucalipto e outras espécies nativas, na qual o eucalipto se destacou em relação as demais espécies estudadas, o que motivou o seu plantio pela Companhia Paulista de Estradas de Ferro, para produção de dormentes (MORA e GARCIA, 2000).

Segundo a IBÁ (2015) o total de área com plantio de árvores para fins industriais no Brasil é 7,74 milhões de hectares, sendo que desse total 5,56 milhões são plantios de Eucalyptus spp (71,9\%), 1,59 milhões são de plantio de Pinus spp (20,54\%) e 0,59 milhões $(7,62 \%)$ é o total de áreas cobertas por outras espécies. Como pode-se observar o gênero Eucalyptus é o mais plantado no país, isso devido seu rápido crescimento em relação a outras espécies florestais comerciais e graças aos investimentos em pesquisas realizadas por instituições públicas e privadas que permitiram conhecer o potencial desse gênero, como a adaptação a diversas condições edafoclimáticas e múltiplos usos. Como resultado o Brasil é uma referência na cultura do eucalipto, com o maior Incremento Médio Anual (IMA) do mundo (39 $\mathrm{m}^{3}$.ha.ano) (IBA, 2015).

As pesquisas florestais são desenvolvidas em diversas áreas, entre elas, a silvicultura. Conforme IBGE (2014) silvicultura é a atividade que trata do estabelecimento, do desenvolvimento e da reprodução de florestas, para as múltiplas aplicações, tais como: a produção de madeira, o carvoejamento, a produção de resinas, a proteção ambiental etc. A silvicultura visa a excelência no desenvolvimento das florestas, por meio do planejamento do reflorestamento, conforme as condições específicas de sítio e finalidade da floresta.

Como parte desse processo destaca-se a densidade populacional do povoamento florestal e sua influência no uso da água, nutrientes e luz. A densidade está relacionada ao espaçamento e arranjo de plantio. Garcia (2010) descreve que espaçamento é a área ocupada por cada planta $\left(\mathrm{m}^{2}\right.$. planta $\left.\left.{ }^{-1}\right)\right)$ e o arranjo é a distância entrelinha e entre planta $(\mathrm{m} \times \mathrm{m})$. Oliveira Neto et al (2010) menciona que o espaçamento ideal é o que permite o melhor desenvolvimento das plantas, na forma e qualidade desejáveis, conforme a finalidade do plantio e o grau de mecanização das operações florestais.

Em relação a nutrição um nutriente muito importante é o potássio (K), pois dentre suas funções destaca-se o auxílio no fechamento e abertura dos estômatos e regulação osmótica (MALAVOLTA, 2006), ou seja, esse elemento químico está diretamente ligado a capacidade das plantas de absorver água.

Em Presidente Prudente a precipitação média é 1254.9 mm (CEPAGRI, 2016), no entanto é mal distribuída, visto que as chuvas se concentram mais entre os meses de outubro a março, sendo o restante do ano caracterizado por baixa pluviosidade, o que reduz a água disponível no solo nessa época, reduzindo o desenvolvimento das plantas.

Dessa forma o presente trabalho teve como objetivo avaliar o desenvolvimento do clone de Eucalyptus urophylla vs. Eucalyptus grandis submetido a diferentes espaçamentos e adubação potássica no município de Presidente Prudente-SP, visando a eficiência do uso da água e nutrientes.

\section{METODOLOGIA}

O presente trabalho foi realizado na ETEC Prof. Dr. Antonio Eufrásio de Toledo, pertencente ao Centro Estadual de Educação Tecnológica Paula Souza (CEETEPS), localizada na Rodovia Raposo Tavares Km 561, bairro Nova Prudente, cujas coordenadas geográficas são de 2210'54" S e 5122'01" O, altitude média 468m em parceria com a Escola Superior de Agricultura Luiz de Queiroz (ESALQ), pertencente a Universidade de São Paulo (USP). 
Em relação ao clima, a região possui temperatura anual média mínima de $14^{\circ} \mathrm{C}$, média de $23,6^{\circ} \mathrm{C}$ e máxima média de $31^{\circ} \mathrm{C}$; pluviosidade média anual de $1254.9 \mathrm{~mm}$, classificação climática de Koeppen Aw, caracterizado por inverno seco e verão chuvoso (CEPAGRI, 2016). O solo da região é o Argissolo (IBGE, 2001).

O experimento foi implantado em 10 de maio de 2014 em uma área de $3159,75 \mathrm{~m}^{2}$. Para o presente trabalho foi utilizado o Delineamento em Bloco Casualizado (DBC), em arranjo fatorial 1x3x2 (uma espécie clonal de eucalipto (Eucalyptus urophylla vs. Eucalyptus grandis), três espaçamentos e duas adubações potássicas), com 3 repetições e 25 plantas por repetição, sendo 9 mudas úteis, totalizando 450 plantas no total, sendo 162 plantas úteis (Tabela 1).

Tabela 01. Delineamento estatístico do teste com o clone Eucalyptus urophylla vs. Eucalyptus grandis submetido a diferentes espaçamentos e adubação potássica no município de Presidente Prudente-SP

\begin{tabular}{|c|c|c|c|c|c|}
\hline Tratamentos & $\begin{array}{l}\text { Arranjo (m } \\
\quad x \mathrm{~m})\end{array}$ & $\begin{array}{c}\text { Espaçamento (m) } \\
\left(\mathrm{m}^{2} \text {. Planta }^{-1}\right)\end{array}$ & $\begin{array}{l}\text { Potássio } \\
\text { (K) }\end{array}$ & Plantas úteis por bloco & $\begin{array}{c}\text { № de } \\
\text { plantas (ha) }\end{array}$ \\
\hline 1 & $3 \times 1$ & 3 & Presente & 9 & 3333 \\
\hline 2 & $3 \times 1$ & 3 & Ausente & 9 & 3333 \\
\hline 3 & $3 \times 2$ & 6 & Presente & 9 & 1666 \\
\hline 4 & $3 \times 2$ & 6 & Ausente & 9 & 1666 \\
\hline 5 & $3 \times 4$ & 12 & Presente & 9 & 833 \\
\hline 6 & $3 \times 4$ & 12 & Ausente & 9 & 833 \\
\hline
\end{tabular}

Obs.: O potássio foi disponibilizado a todas as plantas na adubação de base. O status "Presente" e Ausente" é referente às adubações de cobertura.

Os tratamentos são: espaçamento $3 \times 1 \mathrm{~m}$, com presença de Potássio (K) nas adubações de cobertura (T1), 3x1m, sem presença de Potássio (K) nas adubações de cobertura (T2), 3x2m com presença de Potássio (K) nas adubações de cobertura (T3), 3×2m sem presença de Potássio (K) nas adubações de cobertura (T4), 3x4m com presença de Potássio (K) nas adubações de cobertura (T5) e 3x4 sem presença de Potássio (K) nas adubações de cobertura (T6) (Tabela 2).

Tabela 02. Relação do programa de adubação realizado no teste com o clone Eucalyptus urophylla vs. Eucalyptus grandis submetido a diferentes espaçamentos e adubação potássica no município de Presidente Prudente-SP.

\begin{tabular}{|c|c|c|c|}
\hline Tratamentos & $\begin{array}{c}\text { Adubação de base } \\
\text { (1 mês após o plantio) }\end{array}$ & $\begin{array}{l}\text { 19 adubação de cobertura } \\
\text { (Após } 6 \text { meses do plantio) }\end{array}$ & $\begin{array}{l}\text { 2a adubação de cobertura } \\
\text { (Após } 12 \text { meses do plantio) }\end{array}$ \\
\hline 1 & 53grs NPK 8-28-16 & $\begin{array}{c}\text { 13,33gr/Uréia e } \\
10,00 \mathrm{gr} / \mathrm{Kcl}\end{array}$ & 13,33gr/Uréia e 10,00gr/Kcl \\
\hline 2 & 53grs NPK 8-28-16 & 13,33gr/Uréia & 13,33gr/Uréia \\
\hline 3 & 107 grs NPK 8-28-16 & $\begin{array}{c}\text { 26,66gr/Uréia e } \\
\text { 20,00gr/Kcl }\end{array}$ & $26,66 \mathrm{gr} /$ Uréia e $20,00 \mathrm{gr} / \mathrm{Kcl}$ \\
\hline 4 & 107 grs NPK 8-28-16 & 26,66gr/Uréia & 26,66gr/Uréia \\
\hline 5 & 214 grs NPK 8-28-16 & $\begin{array}{c}\text { 53,33gr/Uréia e } \\
40,00 \mathrm{gr} / \mathrm{Kcl}\end{array}$ & $53,33 \mathrm{gr} /$ Uréia e 40,00gr/Kcl \\
\hline 6 & 214 grs NPK 8-28-16 & 53,33gr/Uréia & 53,33gr/Uréia \\
\hline
\end{tabular}

Obs.: Demais elementos do NPK 8-2-16 utilizado na adubação de base: 3,59\% S, 0,2\% B, 0,2\% Zn, 1,31\% Ca

As atividades silviculturais da implantação do reflorestamento compreenderam o preparo do local e do solo, controle de formigas cortadeiras com o uso do formicida "Mirex" $\left(10 \mathrm{~g} / \mathrm{m}^{2} \mathrm{de}\right.$ formigueiro), imunização das mudas de eucalipto com cupinicida "Evidence", (7,50grs/litro de água), plantio das mudas, irrigação com gel (1gr/litro de água), controle de qualidade de plantio. 
Após o plantio, realizaram-se outras irrigações, o controle de formigas cortadeiras, manutenção da cerca e adubação de plantio.

A recomendação de adubação de plantio foi realizada com base na necessidade de nutrientes observada no Boletim Técnico 100 (RAIJ, 1996) e no resultado da análise de solo, que apontou a necessidade de $60 \mathrm{Kg} / \mathrm{ha}$ de nitrogênio $(\mathrm{N}), 50 \mathrm{Kg} / \mathrm{ha}$ de fósforo $(P)$.

A avaliação realizou-se aos 24 meses após o plantio. Foram coletadas as características dendrométricas: Diâmetro a Altura do Peito (DAP) $(\mathrm{cm})(1,30 \mathrm{~m})$, com uso da suta mecânica Haglof e a altura total (HT) (m), com uso do clinômetro Eletrônico Haglof

Os valores obtidos pelas médias das variáveis foram submetidos ao programa estatístico denominado ASSISTAT (SILVA e AZEVEDO, 2009), onde foi utilizado o procedimento de análise de variância, fatorial e Tukey, a 5\% de probabilidade.

\section{RESULTADOS}

$\mathrm{Na}$ tabela 3 são apresentados os resultados médios determinados para as variáveis diâmetro à altura do peito (DAP), altura total (HT), com a respectiva média geral (MG), Diferença Mínima Significativa (DMS) e coeficientes de variação (CV) e resultados da análise do teste de Tukey a $5 \%$ de probabilidade.

Tabela 03. Características dendrométricas do teste com clone de Eucalipto Eucalyptus urophylla vs. Eucalyptus grandis submetido a diferentes espaçamentos e adubação potássica no município de Presidente Prudente-SP.

\begin{tabular}{cccccc}
\hline Tratamentos & $\begin{array}{c}\text { Arranjo }(\mathrm{m} \times \\
\mathrm{m})\end{array}$ & $\begin{array}{c}\text { Espaçamento }(\mathrm{m})\left(\mathrm{m}^{2} \text {. Planta }\right. \\
1)\end{array}$ & Potássio (K) & DAP $(\mathrm{cm})$ & $\mathrm{HT}(\mathrm{m})$ \\
\hline 1 & $3 \times 1$ & 3 & Presente & $8,12 \mathrm{c}$ & $12,94 \mathrm{a}$ \\
2 & $3 \times 1$ & 3 & Ausente & $8,59 \mathrm{c}$ & $13.01 \mathrm{a}$ \\
3 & $3 \times 2$ & 6 & Presente & $10,14 \mathrm{ab}$ & $13,47 \mathrm{a}$ \\
4 & $3 \times 2$ & 6 & Ausente & $9,07 \mathrm{bc}$ & $14.22 \mathrm{a}$ \\
5 & $3 \times 4$ & 12 & Presente & $11,20 \mathrm{a}$ & $13,57 \mathrm{a}$ \\
6 & $3 \times 4$ & 12 & Ausente & $11,10 \mathrm{a}$ & $14,41 \mathrm{a}$ \\
\hline MG & & & & 9,70 & 13,61 \\
DMS & & & & 1,44 & 3,25 \\
CV (\%) & & & & 5,25 & 8,43 \\
\hline
\end{tabular}

Médias seguidas pela mesma letra não diferem significativamente entre si pelo teste de Tukey a $5 \%$ de significância.

Analisando os resultados da tabela 3 , em relação a variável diâmetro à altura do peito (DAP), observa-se que houve diferença significativa entre os tratamentos. Os tratamentos 5 e 6 foram os que obtiveram maior valor de DAP, já os tratamentos 1 e 2 obtiveram menor valor de DAP, os tratamentos 4 e 3, tiveram valores intermediários, ambos iguais estatisticamente, porém o tratamento 3 também foi igual estatisticamente com os tratamentos 5 e 6 , assim como o tratamento 4 também foi igual estatisticamente com os tratamentos 1 e 2. Analisando os resultados da tabela 3, em relação a variável altura total (HT), observa-se que não houve diferença significativa entre os tratamentos.

$\mathrm{Na}$ tabela 4 são apresentados os resultados médios determinados para o fator espaçamento para as variáveis diâmetro à altura do peito (DAP), altura total (HT), com a respectiva média geral (MG), Diferença Mínima Significativa (DMS) e coeficientes de variação (CV). 
Tabela 04. Médias do DAP e HT, em relação o fator espaçamento.

\begin{tabular}{ccc}
\hline Espaçamentos & DAP $(\mathrm{cm})$ & $\mathrm{HT}(\mathrm{m})$ \\
\hline $3 \times 1$ & $8,35 \mathrm{c}$ & $12,98 \mathrm{a}$ \\
$3 \times 2$ & $9,60 \mathrm{~b}$ & $13,85 \mathrm{a}$ \\
$3 \times 4$ & $11,15 \mathrm{a}$ & $13,99 \mathrm{a}$ \\
\hline MG & 9,70 & 13,61 \\
DMS & 0,81 & 1,82 \\
CV (\%) & 5,25 & 8,43 \\
\hline
\end{tabular}

Médias seguidas pela mesma letra não diferem significativamente entre si pelo teste de Tukey a $5 \%$ de significância.

Analisando os resultados da tabela 4, em relação ao fator espaçamento, observa-se que o espaçamento influenciou a variável diâmetro à altura do peito (DAP), visto que houve diferença significativa. 0 espaçamento $3 \times 4$ obteve maior valor de DAP, o espaçamento $3 \times 1$, obteve o menor valor de DAP e o espaçamento 3×2 obteve valor intermediário de DAP.

Analisando os resultados da tabela 4, em relação ao fator espaçamento, observa-se que o espaçamento não influenciou a variável altura total $(H T)$, visto que não houve diferença significativa

$\mathrm{Na}$ tabela 5 são apresentados os resultados médios determinados para o fator adubação potássica para as variáveis diâmetro à altura do peito (DAP), altura total (HT), com a respectiva média geral (MG), Diferença Mínima Significativa (DMS) e coeficientes de variação (CV).

Tabela 5. Médias do DAP e HT, em relação a adubação potássica.

\begin{tabular}{ccc}
\hline Adubações & DAP $(\mathrm{cm})$ & $\mathrm{HT}(\mathrm{m})$ \\
\hline Com potássio & $9,82 \mathrm{a}$ & $13,33 \mathrm{a}$ \\
Sem potássio & $9,59 \mathrm{a}$ & $13,88 \mathrm{a}$ \\
\hline MG & 9,70 & 13,61 \\
DMS & 0,53 & 1,20 \\
CV $(\%)$ & 5,25 & 8,43 \\
\hline
\end{tabular}

Médias seguidas pela mesma letra não diferem significativamente entre si pelo teste de Tukey a $5 \%$ de significância.

Analisando os resultados da tabela 5, em relação ao fator adubação, observa-se que a adubação potássica não influenciou as variáveis diâmetro à altura do peito (DAP) e altura total $(H T)$, visto que não houve diferença significativa.

\section{DISCUSSÃO}

\section{Espaçamento}

Observou-se que o fator espaçamento influenciou a variável DAP e não influenciou a variável HT de forma significativa (Tabela 3 e 4). O maior espaço entre plantas proporcionou maior DAP nas plantas. Chies (2005) cita que quando é realizado plantio utilizando maior espaçamento, têm-se em determinada idade, plantas com maior diâmetro, se comparado com indivíduos em plantios mais adensados. Machado (2014), ao avaliar o desenvolvimento de povoamento clonal de Eucalyptus urograndis, aos 24 meses de idade, submetido a diferentes arranjos observou que o menor espaçamento gerou menor diâmetro médio por planta. Reiner et al. (2011), avaliando o desenvolvimento de Eucalyptus dunnii em diferentes arranjos não observou diferença significativa nas variáveis diâmetro a altura do peito (DAP), altura total (HT) e volume por planta (VP) aos 24 meses após o plantio, apenas uma tendência de aumento de DAP e HT à medida que que maiores arranjos de plantio foram utilizados. 


\section{Adubação potássica}

Em relação ao fator adubação potássica, observou-se que a presença ou ausência do potássio nas adubações de cobertura, até o presente momento não gerou diferenças significativas nas variáveis DAP e HT, se comparado entre os mesmos espaçamentos (Tabela 3 e 5). Muianga (2013) cita em avaliação de diferentes clones de Eucalyptus urophylla vs. Eucalyptus grandis, submetido a diferentes doses de adubação potássicas ( 0 e $140 \mathrm{Kg} / \mathrm{há}^{-1}$ ), aos 15 meses, que não observou diferença significativa em relação a variável HT. Já em relação a variável DAP, Muianga (2013) descreve que o elemento químico potássio influenciou significativamente o crescimento das plantas, sendo que na omissão total, as plantas apresentaram sempre os menores DAP, se comparados aos tratamentos com adubação potássica. Esse comportamento pode ser explicado pelo fato do potássio desempenhar importante papel na expansão das células cambiais (FROMM, 2010 citado por MUIANGA, 2013)

\section{CONCLUSÃO}

Após a realização da avaliação, observa-se que aos 24 meses após o plantio, dentre os fatores espaçamentos e adubação potássica testados, apenas o espaçamento interferiu significativamente no clone de Eucalyptus urophylla vs. Eucalyptus grandis, em relação a variável DAP, sendo os tratamentos no arranjo $3 \times 4 \mathrm{~m}$ os que obtiveram melhor resultado.

\section{REFERÊNCIAS}

CEPAGRI. Centro de Pesquisas Meteorológicas e Climáticas Ligadas a Agricultura da Unicamp: Clima no município de Presidente Prudente-SP. Disponível em:

< http://www.cpa.unicamp.br/outras-informacoes/clima muni 467.html>. Acesso em 29 jul 2016.

CHIES, D. Influência do espaçamento sobre a qualidade e o rendimento da madeira serrada de Pinus taeda L. 2005. 123p. Tese (Mestrado em Ciências Florestais) - Setor Ciências Agrárias, Universidade Federal do Paraná, Curitiba 2005.

GARCIA, E. A. Caracterização física e química do solo e avaliação do desenvolvimento de plantas de eucalipto em função do espaçamento e da adubação, visando a colheita precoce para utilização em bioenergia. 2010. 98f. Tese de Doutorado. Universidade Estadual Paulista.

IBÁ - Indústria Brasileira de Árvores. Relatório IBA 2015. São Paulo, 2015, 80 p.

IBGE - Instituto Brasileiro de Geografia e Estatística - IBGE: Mapa de solos do Brasil - 2001. Disponível em: <http://mapas.ibge.gov.br/tematicos/solos $>$. Acesso em 29 jul 2016.

IBGE- Instituto Brasileiro de Geografia e Estatística. Produção da Extração Vegetal e da Silvicultura 2014. Rio de Janeiro: IBGE. 2014. 54 p. Disponível em: < http://www.ibge.gov.br/home/estatistica/economia/pevs/2014/>. Acesso em 01 ago 2016.

MACHADO, F. De C. Crescimento inicial de um clone de Eucalyptus grandis em diferentes arranjos de plantio no sistema de curta rotação. 2014. Tese de Doutorado. Universidade Estadual Paulista.

MALAVOLTA, E. et al. Manual de nutrição de plantas. São Paulo: Agronômica Ceres, 2006, 638p.

MORA, A. L.; GARCIA, C. H. - 2000. A cultura do Eucalipto no Brasil. São Paulo - SP, 2000. 112 p. 
MUIANGA, M. R. D. Relação entre crescimento e respostas ecofisiológicas em clones híbridos de Eucalyptus grandis $x$ Eucalyptus urophylla submetidos à diferentes doses de adubação potássica. 2013. Tese de Doutorado. Escola Superior de Agricultura "Luiz de Queiroz.

OLIVEIRA NETO, S. N. de; REIS, G. G. dos; REIS, M. das G. F.; LEITE, H. G.; NEVES, J. C. L. Crescimento e distribuição diamétrica de Eucalyptus camaldulensis em diferentes espaçamentos e níveis de adubação na região de Cerrado de Minas Gerais. FLORESTA, Curitiba, PR, v. 40, n. 4, 755762. 2010.

RAIJ, B.V.; CANTARELLA, H.; QUAGGIO, J.A. \& FURLANI, A.M.C. Boletim Técnico 100:

Recomendações de adubação e calagem para o Estado de São Paulo, 2. Ed. C a m p in a s, I n s t i t u t o Agronômico \& Fundação IAC. 1996. 285p.

REINER, D. A.; SILVEIRA, E. R.; SZABO, M. S. O uso do eucalipto em diferentes espaçamentos como alternativa de renda e suprimento da pequena propriedade na região sudoeste do Paraná. Synergismus scyentifica, Pato Branco, v. 6, n. 1, p. 1-7, 2011.

SILVA, F. DE A. S. E. \& AZEVEDO, C. A. V. DE. Principal Components Analysis in the Software Assistat-Statistical Attendance. In: WORLD CONGRESS ON COMPUTERS IN AGRICULTURE, 7, RenoNV-USA: American Society of Agricultural and Biological Engineers, 2009. 